\title{
Preliminary Exploration to Knowledge System of Standard Science
}

\author{
Xuejing $\mathrm{Wu}^{1, \mathrm{a}}$, Hongli Liang ${ }^{2, \mathrm{~b}}$ \\ ${ }^{1}$ China National Institute of Standardization \\ ${ }^{2}$ University of Chinese Academy of Sciences \\ awuxj@cnis.gov.cn, blianghongli@ucas.ac.cn
}

Keywords: Standard science, Discipline, Knowledge system, Standardization.

\begin{abstract}
The knowledge system of a discipline is a systematic theory system or in other words, a logic system of concept. The establishment of the theory system is deemed as symbol of the maturity of a discipline. Standardization has become a major player of countries in developing their national competitiveness. Establishment of standardization discipline knowledge system has become very urgent for fundamentally lifting competitiveness of China's standards, establishing standardization discipline and training China's professional talents in standardization field. The researches on knowledge system of standard science are so few that nearly no framework of knowledge system of standard science has been proposed so far. We explore the composition of knowledge system of standard science from the composition of humanity knowledge system. Based on this result, this paper makes a thorough inquiry into knowledge composition of standard science, and gives the primary framework of knowledge system of standard science.
\end{abstract}

\section{Introduction}

With historical development and social progress, standardization begins to play a more and more striking role. Today, standardization has become a major player of countries in developing their national competitiveness. Establishment of standardization discipline knowledge system has become very urgent for fundamentally lifting competitiveness of China's standards, establishing standardization discipline and training China's professional talents in standardization field. However, the researches on knowledge system of standard science are so few that nearly no framework of knowledge system of standard science has been proposed so far. Several scholars mentioned the knowledge system when exploring standard science and relevant issues, but just gave a mention and did not carry out systematic exposition.

Qian Xuesen' point of view holds that standard science is still under exploration and its own knowledge system is not available ${ }^{[1]}$. Li Tengjie emphasizes that standard science only exists in manner of economic issues in General Engineering at present, and its concept and category are basically technical things in natural science field, and involve less contents of principles and theorems of sciences in epistemology. So it is thought that standard science has not formed its peculiar disciplinary knowledge system ${ }^{[2]}$. Wang Shouxu thinks that standard science should include theoretical standard science and applied standard science in its development. Only by carrying out study of contents from the two aspects can a relatively complete standard science discipline system be formed. He also points out that currently our study of standard science, regardless of theoretical study or applied study, is poor, and that not any set of complete science theory has been developed in study of standard science ${ }^{[3]}$. Therefore, from studies of the above-mentioned scholars, it is not hard to see that the study of standard science is still at the starting stage, and its knowledge system has not been formed ${ }^{[1-3,5-9]}$. This dissertation, proceeding from composition of human knowledge system, studies composition of disciplinary knowledge system. On the basis of it, it explores knowledge composition of standard science and preliminarily proposes the framework of knowledge system of standard science. 


\section{Composition of knowledge of standard science}

To understand composition of knowledge of standard science, it is firstly needed to understand the components of disciplinary knowledge, while the components of disciplinary knowledge have to be discussed from the structure of human knowledge system. This dissertation, starting from human knowledge system, studies composition of disciplinary knowledge system through composition of modern science and technology system, and then proposes the framework of knowledge system of standard science.

\section{Human knowledge system}

Human knowledge system consists of prescience, science and philosophy. Characteristics of science knowledge are that it can give a reply to not only what it is, but to why it is. In addition, human has also gained a lot of perceptual knowledge and empirical knowledge from practices, which are characterized by that they can only help you know what it is but not answer why it is. So they cannot be included in modern science and technology system. We call such kind of knowledge as prescience ${ }^{[1-3,8,9]}$. Prescience stands at the bottom of the system structure. Today, science and technology mean not only natural science and engineering technology, but also the whole knowledge system for human to know and change the objective world. In this sense, philosophy is the top generalization of the system. Therefore, the three-level knowledge from prescience to modern science technology system and then to philosophy constitutes the whole knowledge system of human being.

\section{Modern science and technology system}

Modern science and technology system was proposed by Qian Xuesen on the basis of system science thought. Every segment of science and technology in modern science and technology system contains three-level knowledge: applied technology (or engineering technology)directly for changing the objective world; technical science directly providing applied technology with theoretical foundation and method; and to a higher level, basic theory for revealing the law of the objective world, namely basic science. Technical science is in fact a transitional bridge from basic theory to applied technology. That is to say, modern science and technology system, on the principle whether a segment of science and technology is one changing the objective world directly or indirectly, can be distinguished from three levels of applied technology, technical science and basic science. Qian Xuesen pointed out that the three-level knowledge structure is also applicable to other segments of science and technology in the same manner ${ }^{[8,9]}$.

\section{Disciplinary knowledge}

Man should first know the objective world before he can change it. Modern science and technology system also follows the viewpoint, and is divided into three levels of basic science, technical science and applied technology on the principle that it changes the objective world directly or indirectly ${ }^{[9]}$. The study finds that basic knowledge in disciplinary knowledge is for directly offering theoretical foundation and method instruction for science and technology, corresponding to the part of technical science in modern science and technology system. Universal knowledge and special field knowledge are directly for solving problems in various fields of disciplines, and provide technical supports for addressing issues of general significance and common character in disciplinary field, corresponding to the part of applied technology in modern science and technology system. General disciplinary knowledge, however, does not surely contain the part of basic theory able to involve revealing the law of the objective world. Acquisition of such kind of knowledge needs multi-discipline joint study and further extraction. So it is concluded that disciplinary knowledge should consist of basic knowledge, universal knowledge and special field knowledge. Of them, what provides theoretical foundation and method instruction for disciplinary field is basic knowledge, namely technical science, and what provides technical support for addressing issues in disciplinary field is universal knowledge and special field knowledge, namely applied technology. The relationships among human knowledge system, modern science and technology system and disciplinary knowledge system are as shown in Fig. 1. 


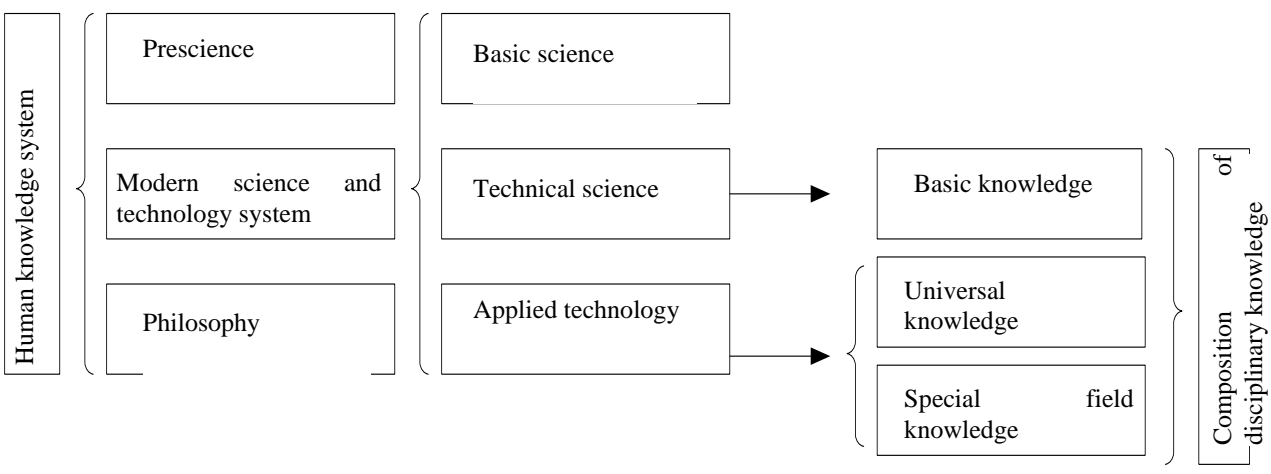

Fig. 1 Composition of Disciplinary Knowledge

\section{Composition of knowledge of standard science}

According to the above-mentioned study, the knowledge of standard science should consist of basic knowledge, universal knowledge and special field knowledge, of which basic knowledge prepares theoretical foundation and method instruction for discipline, and universal knowledge and special field knowledge provide technical support for addressing issues in disciplinary field, corresponding to the part of technical science and the part of applied technology in modern science and technology system respectively. Of them, basic knowledge of standard science includes concept, general knowledge, basic theory and methodology of standardization, and the knowledge of standard science includes knowledge of applied technology, special field and specific standards.

\section{Framework of the knowledge system of standard science}

Standard science is a comprehensive discipline with standards and standardization activities as the study object, to study standardization principle and method and standards' working mechanism. Specifically, standard science studies basic law of standardization, determination and compilation method of elements in standards, standardization management techniques and interactions between standards and technology, economy and society, etc. ${ }^{[4]}$ Once the concept and category of standard science are determined, the boundary for structuring knowledge system framework can be delimited. Knowledge system means the system of knowledge constituted according to certain combination mode and proportion, consisting of different kinds of knowledge, and open, dynamic, general and multi-level. This dissertation is mainly based on the content boundary of standard science and follows the above-mentioned knowledge system structuring principle, to specify composition of the knowledge system of standard science ${ }^{[4-7]}$. The knowledge system of standard science and its position in human knowledge system are as shown in Fig. 2.

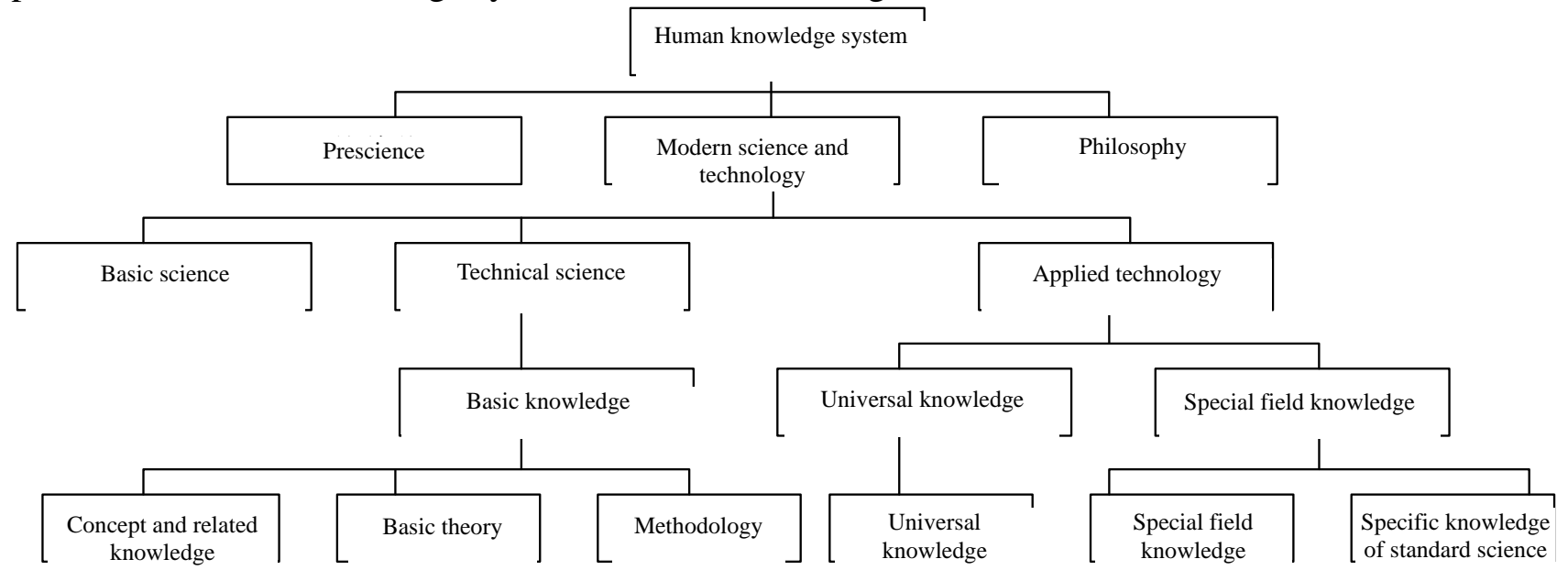

Fig.2 Diagram of knowledge system of standard science and human knowledge system

The framework of the knowledge system of standard science is shown in Fig. 3. The basic concept of standard science and the history and principle of standardization constitute the 
foundation of the whole system. The concept and relevant knowledge of standardization include basic principles of standardization, and the working mechanism and influencing mechanism of standard. The standard science include procedure control method, technology determination method, text drafting method, popularization and application method, and assessment method. Application technical knowledge of standard science includes standardization management technologies, standard formulation procedures, standard drafting rules, standard implementation, and standard literature classification and retrieval. Expertise of standard science covers such fields as material, engineering, electronic information and communication, transportation, agriculture and food, service standardization and construction standardization. Specific knowledge of standard science covers knowledge of various standards, including standards on terminology, symbol, classification, methodology, specification, procedure and guideline, etc.

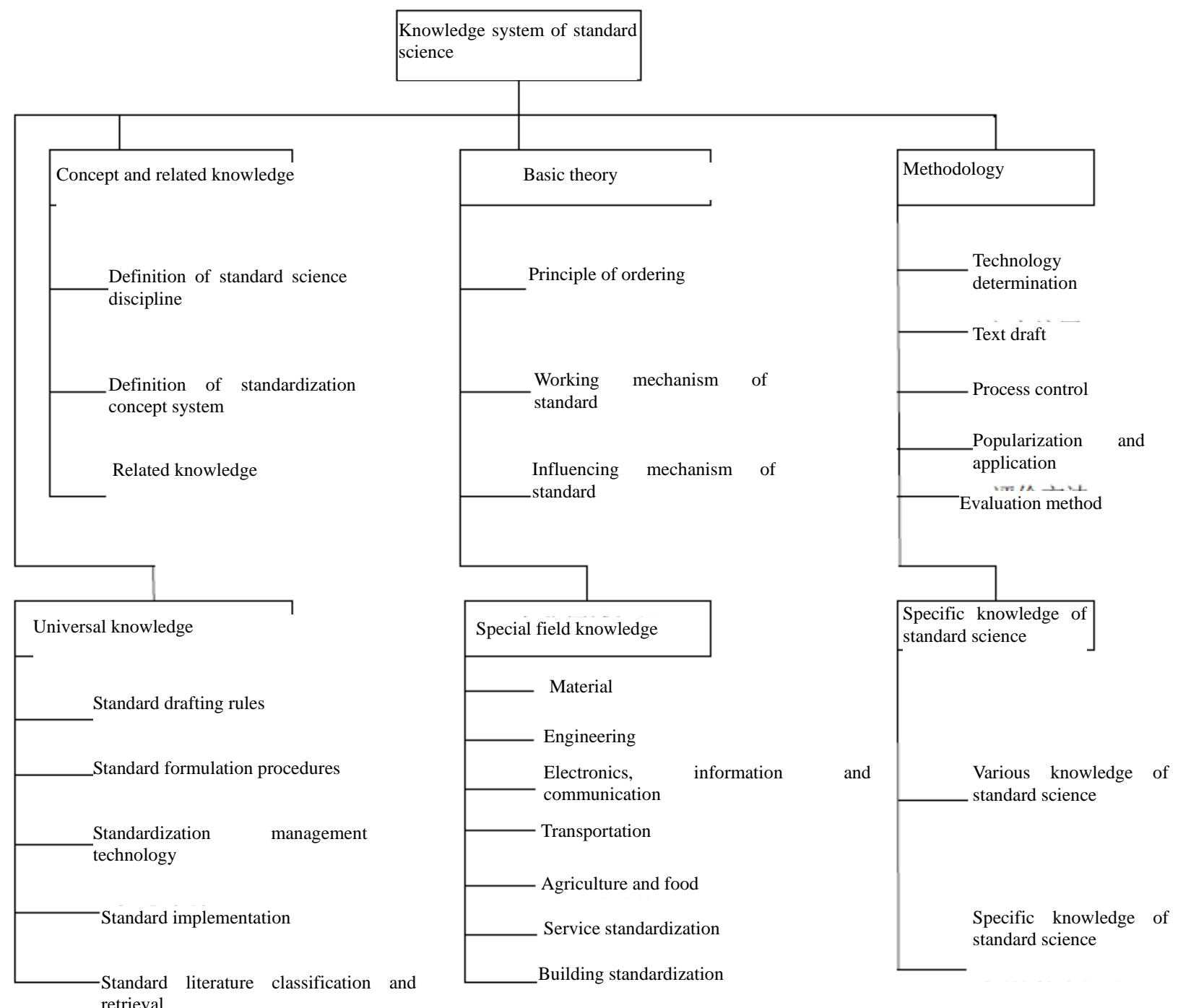

Fig. 3 Knowledge System of Standard Science

\section{Conclusion}

This paper makes a research on the discipline knowledge composition from the point of the composition of human knowledge system and modern science and technology system. Based on the results of above research, it constructs the knowledge system of standard science in accordance with the requirements of systematic and correlated theory and discipline systems, and gives the primary framework of knowledge system of standard science. 


\section{Acknowledgement}

This research was financially supported by the Special Project of Quality Inspection of Public Welfare Industry Research "Study the Methods to Choose and Determine the Key Elements for Technical Standards(No.: 201310225)", "Research on the Classification Analyzation and Rule of Development for Standards Based on the Technical Contents(No.: 201210208)"; Project of Standardization Administration of the People's Republic of China "Research on Transformation Mechanisms for International Standards and Advanced Foreign Standards (European Union)"(No.: 572014B-3395); "Research on Construction of Recommended Standard Systems" (No.: 572014B-3590).

\section{References}

[1] Qian X., Research on Standardization and Standard Science [J]. Standard Life. 2009 (10), pp.7.

[2] Li T., View on Standard Science [J]. Aeronautic Standardization \& Quality. 1980 (6), pp. 12-14.

[3] Wang S., Some Observations on Researches of Standard Science [J]. Popular Standardization. 1994 (2), pp. 15-17.

[4] China National Institute of Standarization. Feasibility Study on the Construction of Standard Science Discipline [R]. 2009.

[5] Bai D., Standard Preparation [M]. Beijing: Standard Press of China. 2009.

[6] Li C., Introduction to Standardization [M]. Beijing: China Renmin University Press. 2005.

[7] Zhang X., System Engineering of Standardization [M]. Beijing: Beijing University of Aeronautics and Astronautics Press. 1992.

[8] Yu J., Contemporary System of Science and Technology and Meta-synthesis Methodology Proposed by Qian Xuesen [J]. Journal of Transportation Systems Engineering and Information Technology. 2001 (1), pp. 267-275.

[9] Hong S., Fang X., Clarification on Some Concept Theories of Discipline Construction [J]. Higher Education Development and Evaluation. 2006 (1), pp 55-57. 